\title{
When to access the capital markets
}

\section{Accessing capital in public equity markets is a tricky business. Here are a few do's and don'ts when planning an initial public offering.}

\author{
Garry E. Menzel
}

Timing is everything. So goes the saying. For biotechnology companies accessing the capital markets, it can mean the difference between success and failure. Unfortunately, it is not just scientific pedigree and breakthrough research that defines the long-term viability of a biotechnology company, but also the interest of institutional investors and the hard cash they provide. Without it, the discovery machine quickly breaks down. And, given the frequent need of cash infusions for drug development, paying attention to Wall Street is a fundamental requirement of business.

As a result, rushing to finance the discovery machine with public money simply because the NASDAQ index is setting records can be a fatal mistake. A stock that should not be public and therefore trades below its initial public offering (IPO) price once the investment banking safety net is removed becomes tainted in the eyes of investors and can hinder success in the larger and more important financings to come. The decision to access the capital markets requires striking a balance between the desire to take advantage of financing windows and knowing when your company is truly ready to go public.

\section{Be prepared}

Apart from the vagaries of the stock market, several prerequisites determine whether a biotechnology company is ready to launch a successful IPO, summarized in Table 1. They should be thought of as gating items, rather than preferable options. Evidence of a compelling and differentiated business model is significant in the current market, which favors biotechnology companies that are able to create sustainable value and move as quickly as possible to provide earnings. Being able to articulate an easily understood equity story to investors is usually a major challenge, but worth the investment in time because the

Garry E. Menzel is head of the biotechnology practice at Goldman, Sachs \& Co., 85 Broad Street, New York, NY 10004

(Garry.Menzel@gs.com).
These extreme changes in the availability of public financing tend to cause many biotechnology companies to access the capital markets at the wrong time in the belief they must take advantage of any window and in the hope that other structural requirements can be resolved later.

process of selling shares on IPO roadshows involves a combination of short management presentations and bankers pitching soundbytes to investors. Furthermore, there are so many biotechnology companies to choose from and so much risk that you need to be a standout to attract attention.

Part of being able to successfully sell an equity story is being able to provide tangible proof that it is real. In biotechnology that means a number of things. The existence of a

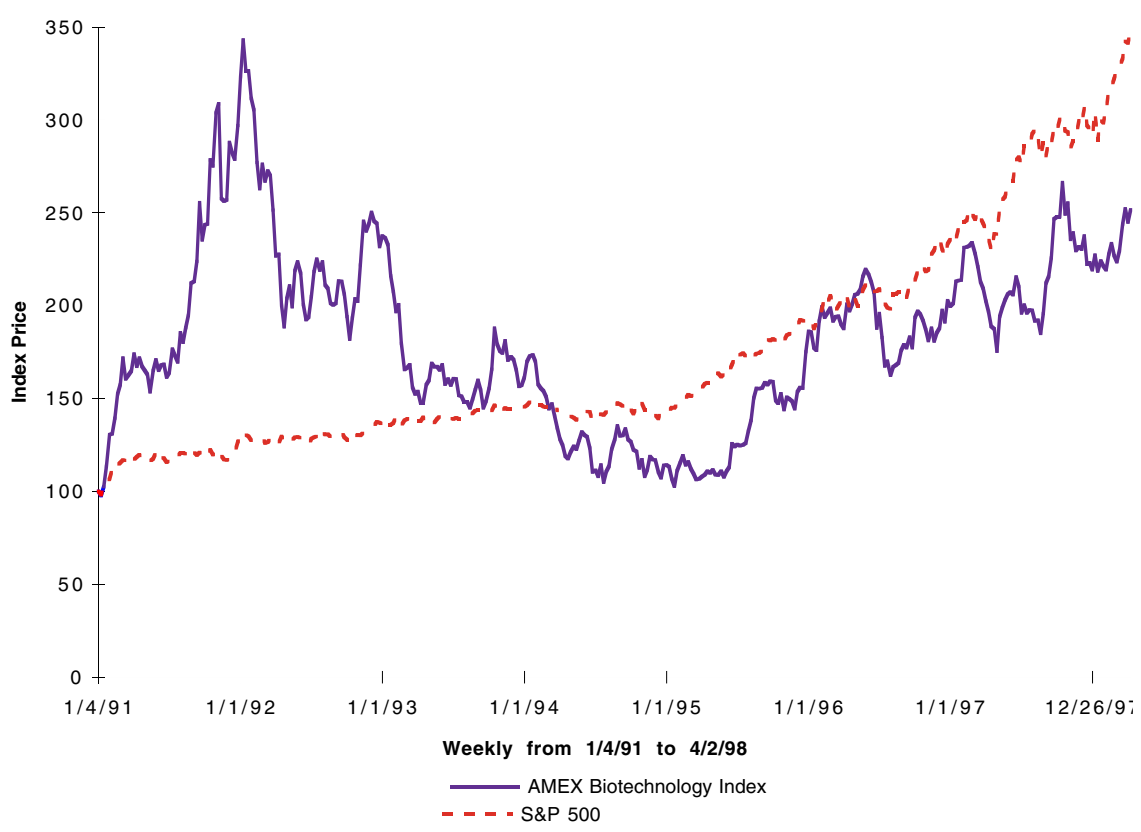

Figure 1. Performance of AMEX biotechnology stocks compared with that of Standard \& Poor's top 500 companies. strong intellectual property portfolio is an absolute in an industry marked by tremendous change. Advanced clinical trials are a significant advantage for therapeutic companies because they provide an investor with hard data that can be used to predict the probability of reaching market. Technology companies need a proof of concept for the platform, usually in the form of a working assay.

Meaningful partnerships with pharmaceutical companies are regarded as an essential validation by investors because they are seen as the historical experts. Meaningful is the operative word here. There are two basic aspects that need attention in a pharmaceutical deal. First, the partnership is best struck with a leader in any given field because they will be seen as the foremost experts. Second, the deal itself should have a bias toward upfront payments and achievable milestones, rather than a back-ended schedule that amounts to no more than an option contract.

Milestones are also important in the context of driving stock performance. Investors 


\section{Can You Afford to Wait?}

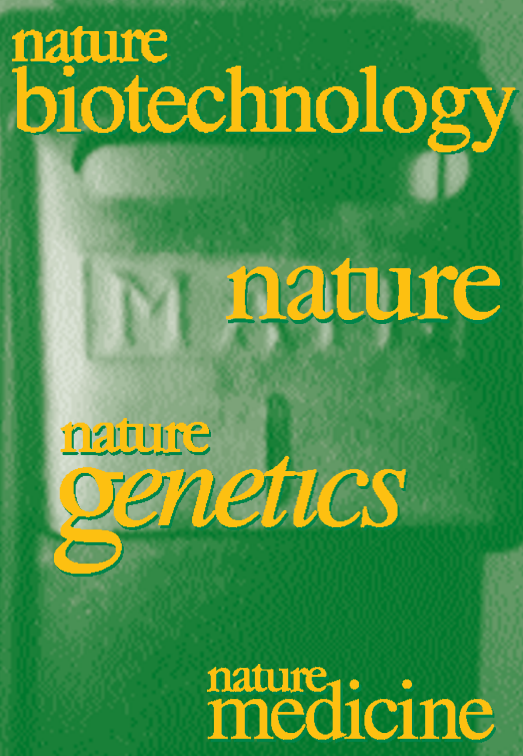

nature

Structural biology

For immediate news affecting

the scientific community,

cutting edge international research,

controversial commentaries and

the newest products and technology.

The Nature family of journals

provides the information

you need, when you need it.

\section{Now.}

For subscription rates and further information, contact:

North \& South America: 8005240384

(Outside the US): 6153773322

fax: 6153770525

email: subscriptions@natureny.com

Japan/Korea: +81332678751 fax: +81332678746

email: subscriptions@naturejpn.com

UK/Rest of the World: +44 (0)1256329242 fax: $+44(0) 1256812358$

email: subscriptions@nature.com

\section{FINANCE}

look not only for an attractive, validated equity story, but also for specific events that will move the stock price once the company is public. Therefore, a company is best served to time its

IPO when there

will be a series of announcements in the socalled aftermarket. In biotechnology, these can include the results of clinical trials, additional partnerships, pending patent applications, and so on, but in all cases they need to be tangible.

The final hurdle is the structure of the company. A strong team of researchers with a reputable scientific advisory board forms the backbone of the organization, but the senior management team is also critical because Wall Street is looking for commercial opportunities rather than beautiful science. There is an obvious link between market value and quality of science, but the ultimate destiny of a company is determined at the top. Thus, before the time is right for an IPO, the company needs to have as many of the key people in place as possible.

\section{When the time is right}

The second half of the balancing act in the timing of biotechnology financing is the availability of funds. As Figure 1 clearly demonstrates, the performance of biotechnology stocks in the last seven years has been highly volatile. Investors became excited about the industry in 1991 without really understanding the economics of scientific research and they funded a large number of new companies. As a result, when several clinical trials failed in 1992, affected company stocks dropped as much as $90 \%$. The biotechnology index was dragged down by the ensuing panic and the financing window was over.

For the next three years, it was extremely difficult to obtain public financing and the number of pharmaceutical deals began to rise. A strong stock market combined with favorable clinical results to reopen the window in early 1995, and a rush of financings followed. The window closed again in June 1996 because of a NASDAQ correction that focused investors on short-term value and, although it reopened again for six months in 1997, disappointing clinical results paved the way for an index crash in October following the Asian crisis that affected broader markets. Since then, the window has remained firmly shut, except to a few, clearly understood, players.

These extreme changes in the availability of public financing tend to cause many
The consequences of a mistake, however, can be disastrous. The stock will likely underperform, have low liquidity, high volatility, poor research coverage, and reduced options for a follow-on financing.

Companies that go public too early can survive in good equity markets, but frequently fail when conditions are poor. The first stocks to suffer when a financing window closes are usually those in the weakest structural position because, in a flight of capital, investors put their money in the safest places. This can create subsequent problems for a company if its stock trades too close to its IPO price for too long. The result is that investors come to see the company as a laggard, and when the larger follow-on financing is required, interest is low.

The belief that it is critical to take advantage of public financing windows in biotechnology is driven by the notion that when the capital markets are not receptive there are no alternatives. This may have been true in 1992 when the industry was younger, but the sector's growing importance as the $\mathrm{R} \& \mathrm{D}$ pipeline for the pharmaceutical industry has provided opportunities for those willing to be creative. For example, scouting the public markets for a reverse merger can provide new technology, skills, and people, as well as cash. Other IPO candidates have focused instead on European investors whose strong desire for biotechnology is not matched by the domestic options available to them. Finding a creative financing alternative usually requires the help of the right investment bank.

\section{The bottom line}

When to access the capital markets is therefore not simply a function of the strength of prevailing conditions. Rather, it is a balance between internal as well as external factors. The optimal scenario is being ready to access the markets at the right time in the cycle. Biotechnology is a long-term industry, and an IPO is only the first in a series of financings. It is therefore important to get the structural pieces in place and to consider all alternatives whenever the need for financing arises. Executives should be advised that while timing may be everything, Wall Street has another saying when it comes to biotechnology: Caveat emptor. 